\title{
Effectiveness of Baking Soda on Vaginal Yeast Infection among Adolescent Nursing Students
}

\section{Esraa Ebrahim Abd-Rabo Abd- Allah', Soad Abd-Elsalam Ramdan², Eman Mohamed Abd El-Hakam $^{3}$ and Ola Abdel-Wahab Afifi ${ }^{4}$}

(1) Nursing specialist at Meet kenana Secondary Nursing School, (2) Professor of Obstetrics \&Gynecological Nursing- Faculty of Nursing-Benha University - Egypt , (3) Assist. Prof. of Obstetrics\&Gynecological Nursing- Faculty of Nursing- Benha University - Egypt, (4) Lecturer of Obstetrics \&Gynecological Nursing- Faculty of Nursing-Benha University - Egypt

\begin{abstract}
:
Vaginal yeast infection is a common condition that affects women during reproductive age. Aim of the study: Was to investigate the effectiveness of baking soda on vaginal yeast infection among adolescent nursing students. Design: Quasi- experimental design was used. Setting: This study conducted at Faculty of Nursing, Benha University. Sample: A Purposive sample was used to conduct the study, included 120 student who fulfill inclusion criteria. Tools: Three tools were used, (1): A self-administered questionnaire that includes: Sociodemographic data, menstrual history and risk factor of disease. (2): Student's knowledge questionnaire and (3): Clinical manifestation of vaginal yeast infection record: (vaginal, urinary and sexual symptoms). Results: There was a statistical significant regarding sexual symptom associated with vaginal yeast infection at pre and post application of baking soda, with $p$ value $\leq 0.05$. Conclusion: There are improvements in all vaginal, urinary and sexual symptoms associated with vaginal yeast infection after application of baking soda Recommendation: Applying educational programs for adolescent females and their mothers to increase awareness about vaginal yeast infection
\end{abstract}

Key words: Baking soda (sodium bicarbonate), Educational program, Vaginal yeast infection.

\section{Introduction:}

Vaginal yeast infection refers to irritation of the vagina due to presences of opportunistic yeast of the genus candida. (Mostly candida albicans) (Sopian et al, 2018). Candida albicans is a saprophytic yeast that exist as apart of the endogenous flora of the vagina (Reichman et al, 2018). Almost 80-90\% of VulvoVaginal Candidiasis (VVC) is caused by candida albicans except that only a minority of cases (10-20\%) is caused by non-C. albicans species, usually candida glabrata (Sobel, 2018).

A general survey in Egypt in recent year, showed that the number of vaginal yeast infection has been dramatically increasing.
About (70-75\%) of women of childbearing age will have at least one episode of vaginal yeast infection during their lifetime. Women younger than 40 years old had a twofold higher risk of getting vaginal yeast infection than the elder. Moreover, age at first sexual intercourse less than 20 increased the risk of suffering vaginal yeast infection by four times. Twenty-five percent of all pregnant women carry Candida organisms in their vagina (Abdullah et al, 2020).

As regards, vaginal yeast infection is caused by inflammation of the vulvar and vaginal epithelium caused by candida species. 
The community of microorganisms that live on the surface of the vagina is referred to as vaginal microbiota. Vaginal microbiota of a healthy reproductive-aged women is a lactobacillus-dominated microflora, producing ample quantity of lactic acid, narrow-ranging bacteriocins, and wideranging hydrogen peroxide (H2O2), suggested to play various important roles in vaginal health. Lactobacilli produce lactic acid as a result of fermentation of carbohydrates, mainly glycogen, present in the vaginal epithelium of menarchal women (Kalia et al, 2020).

Concerning clinical picture experienced by patients with VVC, include intense vulvar pruritus, burning, leukorrhea, dyspareunia, dysuria, edema, vulvovaginal erythema, and vulvovaginal fissures. In addition, patients experience an odorless, thick, white, lumpy vaginal discharge, similar to curd cheese or curdled milk, which adheres to the vaginal walls (Gunther et al, 2018).

Baking soda is one of nonpharmacological agent that helps in naturally balancing out the $\mathrm{PH}$ levels of the vagina. Its alkaline nature helps in killing candida cells that lead to genital yeast infection. This natural vaginal wash helps in speeding up the recovery process with its natural properties ( Ainee, 2020).

The nurse play important role in order to maintain health of women and girls with vaginal yeast infection, facilitating early diagnosis, and increase their awareness in order to prevent vaginal yeast infection. Early identification of vaginal yeast infection helps women to early recover and prevent complication that may occur. The nurse also has a clear role in term facilitating access to, and use of primary care services to prevent occurrence of disease through teaching student practicing good hygiene, wearing cotton under wear, avoid douching and maintain proper diet (Eraky, 2018).

\section{Significant of the study:}

Worldwide, vaginal yeast infection is common health problem that affect women in childbearing period (20-40) years. Approximately $70 \%$ having vaginal yeast infection at their life, about $7 \%$ suffer from recurrence and $10 \%$ of women have asymptomatic vaginal yeast infection with candida spp and do not need treatment (Michelle, 2019). In Egypt, 75\% of women will have at least one episode of vaginal yeast infection, and $40 \%-45 \%$ will have two or more episodes. Approximately $10 \%-20 \%$ of women will have complicated vaginal yeast infection, requiring special diagnostic and therapeutic considerations (Center for disease control and prevention, 2018).

Vaginal yeast infection is common health problem and affects women during reproductive age. If left untreated it may lead to recurrent vaginal yeast infection, or severe infection. Vaginal yeast infection may interfere with menstruation and cause the body to produce a false estrogen. Some women experience worsening of menstrual cramps or a disruption to their period (Gonçalves et al, 2016).

Additionally, untreated vaginal yeast infection may lead to additional health problem as: pelvic inflammatory disease, infertility, ectopic pregnancy, pelvic abscess and Spontaneous abortion. Increasingly, untreated yeast infection may cause skin infection and invasive candidiasis which occur when the yeast infection affects other part of the body as: blood, heart, bones and brain. So this is very urgent to treat vaginal infection and contact with your doctor to control the problem (Dharin et al, 2018). 


\section{Aim of the study:}

The aim of the present study was to investigate the effectiveness of baking soda on vaginal yeast infection among adolescent nursing students.

\section{Research Hypothesis:}

Adolescent nursing students who suffering from vaginal yeast infection would have improved and relieved symptoms after using baking soda.

\section{Subjects and Method:}

\section{Research Design:}

A quasi- experimental design was used to fulfill this study.

\section{Research setting:}

The study was conducted at Faculty of Nursing, Benha University. The Faculty of Nursing consists of four academic years in addition to, internship year to obtain bachelor's degree in nursing science.

\section{Sampling:}

Sample type: A purposive sample was used.

\section{Sample size:}

- Total number of female nursing students that suffer from vaginal yeast infection and confirmed by medical diagnosis in 20192020 was 1205.

- Total sample include $10 \%$ of total number of female nursing students who fulfill inclusion criteria at Faculty of Nursing Benha University 2019-2020. (120) students.

\section{Inclusion criteria:}

- Nursing students who suffer from vaginal yeast infection that confirmed by medical diagnosis.

- Willing to participate in the study.

\section{Exclusion criteria:}

- Pregnant women

- Having other medical or chronic disease as (diabetes, anemia...etc.).

\section{Tools of data collection:}

Three tools were used for collecting data.

Tool I: A self-administered questionnaire:

This tool was designed by the researcher after reviewing the relative literature. It was designed in Arabic language, it consist of three parts as follow:

Part (1): Socio demographic data such as : age, residence, marital status, academic year and source of knowledge.)

Part (2): Menstrual history such as: Age of menarche, period between each menses, duration of menses, amount of blood, nature of blood and color of blood.

Part (3): Risk factor of vaginal yeast infection: This included 15 points.

Tool II: Student's knowledge questionnaire :(pre-posttest)

It included (19 questions) to assess level of student's knowledge regarding anatomy and physiology of female reproductive system and vaginal yeast infection.

\section{Scoring system:}

All knowledge variables were weighted according to items included in each question, the answer of question were classified into 2 categories, the answer would have score (1) for correct answer and (0) for incorrect answer or don't know.

Total knowledge score was classified as following:

- $\operatorname{Good}(<75 \%$ correct answer)

- Average (50-75\% correct answer)

- Poor $(<50 \%$ correct answer $)$

Tool III: Clinical manifestation of vaginal yeast infection record (pre -post test): Consist of three parts as following: 
Part (1): Vaginal symptoms: it included (7questions).

Part (2): Urinary symptoms; it included 8questions.

Part (3): Sexual symptoms: it included 5questions.

\section{Ethical consideration:}

The aim of the study was explained to each student before applying the tools to gain their confidences and trust. An oral consent was obtained from each student to participate in the study and withdrawal when she needs. The study was not having any physical, social, or psychological risk on the participant. The data collected and treated confidentially. Each will be informed about time throughout the study.

\section{Tools validity:}

The tools of data collection were thoroughly reviewed by three experts, two in Obstetrics \& Woman's health nursing and obstetrician to test the content validity, modifications were carried out according to the panel' judgments on clarity of sentences and the appropriateness of content.

\section{Tools Reliability:}

Reliability of tools was tested by using Cronbach's alpha coefficient test, which revealed that the tools consisted of relatively homogenous items as showed by the moderate to high reliability of each tool. Cronbach's alpha of knowledge structured questionnaire was (0.76) and (0.86) for manifestation (clinical record).

\section{Pilot study:}

The pilot study was conducted on $10 \%$ of the total sample (12) female student. It was conducted to test the simplicity, feasibility, clarity and applicability, of the developed tool, also to find out the possible obstacles and problem that face the researcher and interfere with data collection. According to the result of the pilot study, required modification was done. The pilot sample was excluded from the study.

\section{Field work:}

Data was collected through four phases. The following phases were adopted to fulfill the aim of the current research: preparatory, assessment, implementation and evaluation phases. The field work of the current study was carried out from beginning of March to the end of December 2020. Data were collected from beginning of March to the end of same month, then from beginning of May to the end of same month, then from beginning of October to the end of December 2020. Due to absence of student as a result of presence of covid-19 virus.

\section{Assessment phase:}

1. The researcher visited Benha Faculty of Nursing three days weekly. Students who had vaginal yeast infection was screened and interviewed by the researcher, the researcher was introduced herself to the students, then explained purpose of the study.

2. The researcher informed each student about the study in simple term then explained the tool content and the form was filled by the student.

3. Student was given tool to fulfill it.

4. The researcher follow the following steps to collect the data:

a) The researcher gave the student tool (I) to collect data about socio - demographic data, obstetrical history, menstrual history, risk factor of vaginal yeast infection This tool was fulfilled in about (5-10) minutes.

b) Then tool (II) was given to each student to assess knowledge level about anatomy of female reproductive system, vaginal yeast infection and its remedial measures (prepost test ). This tool took about (15-20) minutes to be fulfilled. 
c) Finally, tool (III) was distributed to determine clinical manifestation of vaginal yeast infection (pre -post test ). This took about (10-15) minutes.

\section{Implementation phase:}

- The researcher provided health education to the student about anatomy of female reproductive system, vaginal yeast infection and its remedial measures by using appropriate educational methods such as, discussion and brochure.

- Two sessions were applied (theoretical and practical sessions) about vaginal yeast infection and how to use baking soda to relieve symptoms of vaginal yeast infection.

- The first session included, anatomy of female reproductive system as (component of external reproductive system of female, component of internal reproductive system of female, definition of vagina, function of vagina and normal vaginal $\mathrm{PH}$ ) and vaginal yeast infection as (definition, incidence, risk factor, causes, complication of vaginal yeast infection, treatment and prevention) .

- The second session included remedial measures that relief symptoms of vaginal yeast infection particularly sodium bicarbonate.

- During the second session, the studied student was trained about how to use sodium bicarbonate to relieve vaginal yeast infection according to the following steps:

a) Before using baking soda student should recommended to test the effect on a small patch of skin at least 10 minutes before taking baking soda bath (sensitivity test)

b) Sodium bicarbonate was used in a sitz bath or by vaginal irrigation.

c) The site bath or vaginal irrigation was prepared by adding about (6-12g /L water) then sit in a bath. d) The mixture should be dissolve thoroughly.

e) The duration of use sodium bicarbonate took about (10-40) minutes, two or three time /day for two weeks. (Felix, 2019)

f) At the end of second session redemonstration was done to confirm that the student aquired knowledge about using of sodium bicarbonate.

\section{Evaluation phase and follow up:}

After two weeks, post-test was done using the same format of pre-test: tool II (student's knowledge questionnaire) to evaluate the effect of educational session in improving the student's knowledge level regarding anatomy of female reproductive system, vaginal yeast infection and Tool III (clinical manifestation of vaginal yeast infection used to evaluate effect of using baking soda in relieving clinical manifestation of vaginal yeast infection .

\section{Statistical analysis:}

Data was verified prior to computerized entry. The statistical package for the social sciences (SPSS version 22) was used for that purpose followed by data tabulation and analysis.

\section{Results}

Table (1): Shows socio demographic characteristics of the studied sample. It was cleared that less than half $(49.2 \%)$ of studied sample were in age group 21- years with a mean age of $20.82 \pm 1.36$ years. As regards the residence, less than two-thirds $(60.8 \%)$ of them lived in rural areas. Furthermore, the majority of them (80.8\%) were single. Regarding the academic year, more than onethird $(34.2 \%)$ of them were in fourth grade. Moreover; more than fifth $(20.8 \%)$, less than one-fifth $(18.3 \%)$ and more than quarter of them were in first, second and third grades respectively.

Table (2): Indicates that mean age of menarche for majority of student was at 11-13 
years and the mean age of menarche was $12.46 \pm .99$ years. In addition; the mean menstrual cycle of them was $30.70 \pm 5.40$ days. Moreover; the mean duration of menstruation of them was $4.63 \pm 1.22$ days. Regarding amount of blood, less than two-thirds $(60.0 \%)$ of students had mild amount, and the majority (88.3) of them had liquid menstrual blood. Increasingly, the majority $(94.2 \%)$ of them had dark red color of blood. Finally, less than three-quarters (72.5\%) had regular menstruation.

Table (3): Reveals, the commonest risk factor that aggravate vaginal yeast infection among the studied sample was " Not sleeping enough hours during the day" which account for the majority of them $(80.8 \%)$, "Drinking soft drinks regularly" "Wearing tight clothing", "Always eating spicy food" and "Suffering from stress and psychological problems" which account for more than three-quarters $(75.8 \%)$, less than three-quarters $(73.3 \%)$, more than half $(56.7 \%)$ and $(55.8 \%)$ of them respectively.

Figure (1): Displays that, (10.0\%) and $(68.4 \%)$ of studied sample had good knowledge regarding anatomy of female reproductive system and vaginal yeast infection at pre-intervention and postintervention phases respectively. While, it was revealed that $(70.8 \%)$ and $(20.8 \%)$ of studied sample had poor knowledge regarding anatomy of female reproductive system and vaginal yeast infection at pre-intervention and post-intervention phases respectively.

Table (5): Clears that there was a highly statistical significant difference between the results of post-intervention phase compared to pre- intervention phase in favor of postintervention regarding vaginal symptoms associated with vaginal yeast infection of studied sample about with $\mathrm{p} \leq 0.001$.

Table (1) Distribution of the studied sample according to their socio demographic characteristics $(\mathbf{n}=\mathbf{1 2 0})$.

\begin{tabular}{|c|c|c|}
\hline Socio demographic characteristics & No & $\%$ \\
\hline \multicolumn{3}{|l|}{ Age by years: } \\
\hline $19-$ & 46 & 38.3 \\
\hline $21-$ & 59 & 49.2 \\
\hline$\geq 23$ & 15 & 12.5 \\
\hline \multicolumn{3}{|c|}{ Mean \pm SD $=20.82 \pm 1.36$} \\
\hline \multicolumn{3}{|l|}{ Residence: } \\
\hline Rural & 73 & 60.8 \\
\hline Urban & 47 & 39.2 \\
\hline \multicolumn{3}{|l|}{ Marital status: } \\
\hline Single & 97 & 80.8 \\
\hline Married & 23 & 19.2 \\
\hline Divorced & 0 & 0.0 \\
\hline Widowed & 0 & 0.0 \\
\hline \multicolumn{3}{|l|}{ Academic year: } \\
\hline First grade & 25 & 20.8 \\
\hline Second grade & 22 & 18.3 \\
\hline Third grade & 32 & 26.7 \\
\hline Fourth year & 41 & 34.2 \\
\hline
\end{tabular}


Table (2): Distribution of the studied sample regarding their menstrual history $(\mathrm{n}=120)$.

\begin{tabular}{|c|c|c|}
\hline Menstrual history & No & $\%$ \\
\hline \multicolumn{3}{|l|}{ Age of menarche: } \\
\hline 10 & 2 & 1.7 \\
\hline $11-13$ & 105 & 87.5 \\
\hline$>14$ & 13 & 10.8 \\
\hline \multicolumn{3}{|c|}{ Mean + SD $=12.46+99$} \\
\hline \multicolumn{3}{|l|}{ Menstrual cycle: } \\
\hline$\leq 20$ days & 10 & 8.3 \\
\hline $21-35$ days & 87 & 72.5 \\
\hline$>35$ days & 23 & 19.2 \\
\hline \multicolumn{3}{|c|}{ Mean + SD $=3070+5.40$} \\
\hline \multicolumn{3}{|c|}{ Regularity of menstrual cycle: } \\
\hline Regular & 87 & 72.5 \\
\hline Irregular & 33 & 27.5 \\
\hline \multicolumn{3}{|l|}{ Duration of menstruation: } \\
\hline$<3$ days & 16 & 13.3 \\
\hline $3-5$ days & 93 & 77.5 \\
\hline$>5$ days & 11 & 9.2 \\
\hline \multicolumn{3}{|c|}{ Mean \pm SD $=4.63 \pm 1.22$} \\
\hline \multicolumn{3}{|l|}{ Amount of blood: } \\
\hline Mild ( $\leq 2$ perineal $\mathrm{pad} /$ day $)$ & 72 & 60.0 \\
\hline Moderate (3-4 perineal pad/day) & 32 & 26.7 \\
\hline Severe ( $\geq 5$ perineal pad/day) & 16 & 13.3 \\
\hline \multicolumn{3}{|l|}{ Limuidity of hlond: } \\
\hline 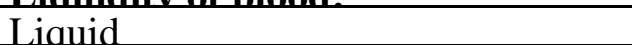 & 106 & 88.3 \\
\hline Clots & 14 & 11.7 \\
\hline \multicolumn{3}{|l|}{ Color of hlond: } \\
\hline Bright red & 7 & 5.8 \\
\hline Dark red & 113 & 94.2 \\
\hline
\end{tabular}

Table (3): Distribution of the studied sample according to presence of risk factors that of vaginal yeast infection $(n=120)$.

\begin{tabular}{|l|c|c|}
\hline \multicolumn{1}{|c|}{ Risk factors* } & No & \% \\
\hline Taking medication as antibiotics or cortisol often & 21 & 17.5 \\
\hline Suffering from chronic diseases such as diabetes & 3 & 2.5 \\
\hline Suffering from another infection such as a urinary tract infection & 34 & 28.3 \\
\hline Always eating spicy food & 68 & 56.7 \\
\hline Drinking soft drinks regularly & 91 & 75.8 \\
\hline Wearing underwear that contains synthetic fibers & 59 & 49.2 \\
\hline Wearing tight clothing & 88 & 73.3 \\
\hline Using of birth control pills & 9 & 7.5 \\
\hline Using vaginal douche regularly & 11 & 9.2 \\
\hline Suffering from stress and psychological problems & 67 & 55.8 \\
\hline Not changing the diaper regularly during the menstrual cycle & 42 & 35.0 \\
\hline Not sleeping enough hours during the day & 97 & 80.8 \\
\hline Not washing underwear in hot water or exposing it to sunlight & 61 & 50.8 \\
\hline
\end{tabular}

* Results not mutually exclusive 


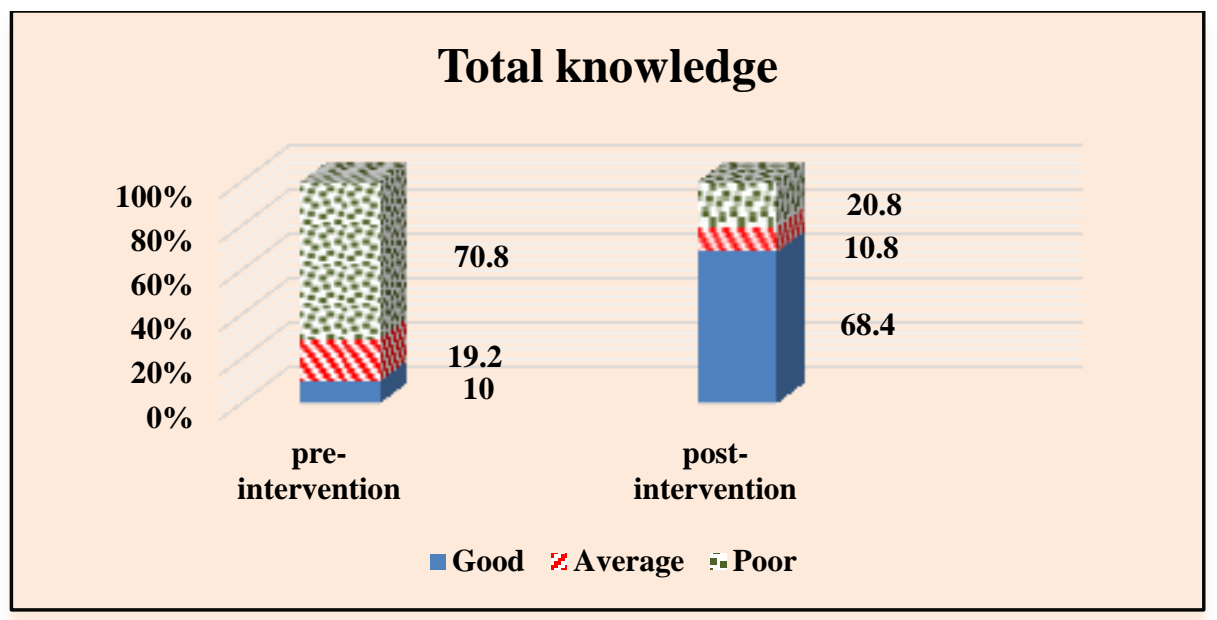

Figure (1): Percentage distribution of studied sample regarding their total knowledge score about vaginal yeast infection at pre- intervention, post- intervention phases $(n=$ 120).

Table (4): Distribution of studied sample regarding their symptoms associated with vaginal yeast infection at pre and post application of baking soda $(n=120)$

\begin{tabular}{|c|c|c|c|c|c|c|c|c|c|c|}
\hline \multirow{3}{*}{ Practices items } & \multicolumn{4}{|c|}{ Pre-intervention } & \multicolumn{4}{|c|}{$\begin{array}{l}\text { Post-intervention } \\
\text { After two weeks) }\end{array}$} & \multirow{3}{*}{$\mathrm{X} 2$} & \multirow{3}{*}{ p-value } \\
\hline & \multicolumn{2}{|c|}{ Yes } & \multicolumn{2}{|c|}{ No } & \multicolumn{2}{|c|}{ Yes } & \multicolumn{2}{|c|}{ No } & & \\
\hline & No & $\%$ & No & $\%$ & $\mathbf{N}$ & $\%$ & No & $\%$ & & \\
\hline 1. Do you feel itchy or itchy in the vaginal area? & 120 & $\begin{array}{l}100 . \\
0\end{array}$ & 0 & 0.0 & 95 & 79.2 & 25 & 20.8 & 27.90 & $\leq 0.001 * *$ \\
\hline $\begin{array}{l}\text { 2. Do you feel a burning sensation in the vaginal } \\
\text { area? }\end{array}$ & 113 & 94.2 & 7 & 5.8 & 87 & 72.5 & 33 & 27.5 & 20.28 & $\leq 0.001 * *$ \\
\hline 3. Is there redness in the vaginal area? & 108 & p0.0 & 12 & 10.0 & 84 & 70.0 & 36 & 30.0 & 15.00 & $\leq 0.001 * *$ \\
\hline 4. Are the secretions have an offensive odor? & 120 & 100. & 0 & 0.0 & 93 & 77.5 & 27 & 22.5 & 30.42 & $\leq 0.001 * *$ \\
\hline 5. Is there a swelling of the vagina? & 85 & 70.8 & 35 & 29.2 & 39 & 32.5 & 81 & 67.5 & 35.30 & $\leq 0.001 * *$ \\
\hline 6. Does the secretion look like cheese? & 76 & 53.3 & 44 & 36.7 & 30 & 25.0 & 90 & 75.0 & 35.75 & $\leq 0.001 * *$ \\
\hline 7.Are there watery (transparent) secretions? & 44 & 36.7 & 76 & 63.3 & 19 & 15.8 & 101 & 84.2 & 13.45 & $\leq 0.001 * *$ \\
\hline
\end{tabular}

\section{Discussion}

Vaginal yeast infection is a fungal infection that causes irritation, discharge and intense itching of the vagina and the vulva, nearly $75 \%$ of all adult women had at least one genital yeast infection in all life time. Yeast infection is caused by an overgrowth of 
normally growing fungi in the vagina (Foxman and Muraglia, 2016). Baking soda could use for vaginal yeast infection management through effectively balancing the vagina`s naturally occurring bacterial and yeast levels, as a result the infection will be cured (Abd El Razek\&Al-Zaru, 2016).

The current study aimed to investigate the effectiveness of baking soda on vaginal yeast infection among adolescent nursing students. This aim was significantaly achived through a quais-expermintal design. The finding of this study were accepted the research hypothesis which was, adolescent nursing students who suffering from vaginal yeast infection will have improved and relieved symptoms after using baking soda.

Regarding personal characteristics of studied sample, the result of the present study revealed that less than half of studied sample were in age group 21-22 years with a mean age of $20.82 \pm 1.36$ years. As regards the residence, less than two-thirds of them lived in rural areas. Furthermore, the majority of them were single. Regarding the academic year, more than one-third of them were in fourth grade. Moreover; more than fifth, less than one-fifth and more than quarter of them were in first, second and third grades respectively.

This result is in accordance with (Youness \& Omar, 2017), who applied their study in Egypt to assess the effectiveness of planned educational program on vaginitis and its preventive measures on adolescent female nursing student's knowledge, showed that the mean age of studied sample was 19.2 \pm 0.53 , the great majority ( $97.5 \%)$ of them were unmarried and near to half $(48.1 \%)$ of studied students lived in rural areas.

Also, (Abdelnaem et al., 2019), who carried out their study in Egypt to evaluate the effect of self-care guidelines on knowledge, quality of life and practices among faculty of nursing students with vaginal infection, found that more than one half $(53.3 \%)$ of studied students had an age group from 20-22 years, the majority $(82.7 \%)$, of them lived in rural areas, the great majority $(94.4 \%)$ of studied students were single. This similarity in result back to working on the same sample type (University's students).

On the other hand, the result of current study disagreed with (Said et al., 2019), who achieved their study in Egypt to evaluate the education intervention guideline on knowledge and self-care practice for women with vulvovaginitis, illustrated that more than one half $(58.5 \%)$ of studied women had an age greater than 30 years old with a mean of $24.68 \pm 5.38$, less than one quarter $(24.6 \%)$ of them had a university level of education, more than one half $(53.8 \%)$ of studied women were lived in rural areas. This difference back to change in sample type (working on women and not students as current study).

Concerning menstrual history of studied sample, current study reported that mean age of menarche for majority of student was at 11-13 years and the mean age of menarche was 12.46 \pm .99 years. Also, about two thirds of students was embraced at menarche. In addition; the mean menstrual cycle of them was $30.70 \pm 5.40$ days. Moreover; the mean duration of menstruation of them was $4.63 \pm 1.22$ days. Regarding amount of blood, less than two-thirds of students had mild amount, and the majority of them had liquid menstrual blood. Increasingly, the majority of them had dark red color of blood. Finally, less than three-quarters had regular menstruation.

These finding were congruent with (Sharma et al., 2016), who carried out their study in Pokhara Valley to determine menstrual pattern among adolescent girls, and reported that the majority $(74.2 \%$ and $88.8 \%$ ) of participants had a menstrual cycle from 21- 
35 days and its duration ranged from 3-7 days respectively.

Also, these result came in the same harmony with, (De Sanctis et al., 2019), who achieved their study in Italy to explore the independent role of age at menarche on menstrual abnormalities among adolescents, showed that the majority (85.5\% and $77.6 \%$ ) of studied students had a menstrual cycle from 21-35 days and with a duration from 4-6 days respectively. And near to previous results (Orabi, 2018), who implemented study to assess the knowledge of female university students about vulvovaginal candidiasis (VVC), showed that the mean age of menarche for studied sample was $12.30 \pm 1.88$, the majority ( $66 \%$ and $69 \%$ ) of them had a regular menstruation and their duration ranged from 5-6 days respectively.

Referring to risk factors for vaginal yeast infection, the actual study reveals that , the commonest risk factor that aggravate vaginal yeast infection among the studied sample was " Not sleeping enough hours during the day" which account for the majority of them, "Drinking soft drinks regularly" "Wearing tight clothing", "Always eating spicy food" and "Suffering from stress and psychological problems" which account for more than three-quarters, less than threequarters, more than half $(56.7 \%)$ and $(55.8 \%)$ of them respectively. Increasingly less than on sixth reported using antibiotics and the minority of them reported diabetes mellitus.

In this respect, the present finding were supported by (Singh \& Singh, 2018), who carried out their study to assess the risk factors contributing vaginitis in women of reproductive age group, showed that the majority $(70 \%)$ of participants reports wearing tight clothes as a risk factors for vaginal infection, less than on sixth $(12 \%)$ reported using antibiotics and $6 \%$ of them reported diabetes mellitus. This explained the similarity in characterstic of studied sample.

On opposite of that the finding of present study was inconsistence with, (Abd ElRazek \& Al-Zaru, 2016), who conducted their study in Jordan to determine the efficacy of sodium bicarbonate in early management and improvement of vaginal yeast infection among women and displayed that great majority $(94 \%$ and $85 \%)$ of risk factors for vaginal yeast infection were industrial fibers of underwear and wearing tight underwear respectively. Taking antibiotics frequently responsible for the majority $(71 \%)$ of risk factors and vaginal douches responsible for one half of risk factors.

According to knowledge of studied sample about anatomy of female reproductive system and vaginal yeast infection, present study findings cleared that there was a highly statistical significant difference between the results of post-intervention phase compared to pre- intervention phase in favor of postintervention regarding studied sample's knowledge about anatomy of female reproductive system and vaginal yeast infection with $p \leq 0.001$. Where, the minority and more than two-thirds of studied sample had good knowledge regarding anatomy of female reproductive system and vaginal yeast infection at pre-intervention and postintervention phases respectively. While, it was revealed that less than three-quarter and more than one-fifth of studied sample had poor knowledge regarding anatomy of female reproductive system and vaginal yeast infection at pre-intervention and postintervention phases respectively.

Theses finding was matching with (Abd El-Razek \& Al-Zaru, 2016), who revealed that the great majority of studied women don't know the correct answer about definition, causes, risk factors, and symptoms 
of vaginal infection in pretest. That transmitted to the majority of them know correct knowledge about all above items in posttest, with statistical significant difference between them $p$-value $\leq 0.001$. And (Said et al., 2019) showed statistical significant difference between pre and posttest regarding knowledge about vulvovaginitis p-value $\leq$ 0.001 .

\section{Also, (Youness \& Omar, 2017)} clarified that the majority of studied student in pretest don't had a good knowledge about causes, symptoms, diagnosis and complications of vaginal infection in pretest. And the majority of them had a good knowledge about all previous items in posttest with statistical significant difference between pre and posttest $p$-value $\leq 0.001$. All previous results reflect the importance of supporting all females with knowledge about genial tract infection through educational programs.

On the same line, (Malfasari et al., 2019), who carried out their study in Egypt to assess the knowledge of female university students about VVC and examine the effect of instructional program on their knowledge among female university students, showed that the participants had a poor knowledge in pretest and had a good knowledge about VVC in posttest with statistical significant difference between them $p$-value $\leq 0.001$.

Concerning to vaginal, urinary symptoms associated with vaginal yeast infection at pre and post application of baking soda, the current study clarifies that there were improvement in all vaginal and urinary symptoms after application of baking soda with highly statistical significant difference between pre and after application regarding all symptoms $\mathrm{p}$-value $\leq 0.001$. Increasingly there was statistical significant regarding sexual symptoms associated with vaginal yeast infection at pre and post application of baking soda, with $\mathrm{p}$ value $\leq 0.05$.
In agreement with previous results (Moshfeghy et al., 2020), who applied their study in Iran to determine the association of sexual function and psychological factors including depression, anxiety, and stress in women with vulvovaginal candidiasis, illustrated that there was association between vulvovaginal candidiasis and sexual function as orgasm, satisfaction and pain p-value $0.042,0.005$ and 0.043 respectively.

Also, (Şimşir et al., 2019), who carried out their study in Turkey to investigate the effects of bacterial vaginosis, which is the most frequent vaginal infection in women, and its treatment on sexual functions, and concluded that sexual dysfunction was more common in patients with bacterial vaginosis and improvement was seen in some sexual functions with treatment.

This finding agreed with (Abd El-Razek \& Al-Zaru, 2016), who clarified that vaginal washing by baking soda/ sodium bicarbonate help to reduce vaginal yeast infection particularly when used in combination with medication. This similarity reflects importance of applying this study to other areas to support using of baking soda in combination with medication in healing vaginal yeast infection.

\section{Conclusion}

There are improvements in all vaginal, urinary and sexual symptoms associated with vaginal yeast infection after application of baking soda with statistical significant difference between pre and post application regarding all symptoms. There is an improvement in total knowledge about vaginal infection after implementation of education program. there was a highly statistically significant relation between total knowledge score regarding vaginal yeast infection and (marital status) of the studied sample $(p \leq 0.001)$, while there was a statistically significant relation between total 
knowledge score and (age \& academic year) (P> 0.05) at pre-intervention phase. On the other side, there was a statistically significant relation between total knowledge score and only (age) of the studied sample at postintervention phases $(\mathrm{P}>0.05)$.

\section{Recommendations}

- Applying educational programs for adolescent females and their mothers to increase awareness about vaginal yeast infection.

- Develop a special health center for adolescent females that motivate them to seek prevention, early diagnosis and treatment of vaginal infection that may have positive impact on their future health.

- Provide outpatient unite and $\mathrm{MCH}$ centers with brochures and posters of vaginal yeast infection prevention.

- Nurses should practice their educator's role in terms of health education about vaginal yeast infection and it's nonpharmacological treatment.

- Assessment of risk factors of vaginal yeast infection should be included in routine women's care that is provided at the outpatient clinics and maternal \& child health $(\mathrm{MCH})$ centers.

- Health care professionals should pay attention to the value of baking soda as a treatment of vaginal infection, besides standard medication.

\section{Further research:}

More studies and researches needed to confirm the effectiveness of baking soda on vaginal yeast infection using larger sample size

\section{References:}

Abd El-Razek, A., \& Al-Zaru, I. (2016). Efficacy of Sodium Bicarbonate in Early Management and Reduce Vaginal Yeast Infection among Women in Jordan: A Quasi-
Experimental Study. 2(5), 29-36.

\begin{abstract}
Abdelnaem S. Ali, Hamido, S., \& Mohasib, Hoda Abd Elazim Mohamed, (2019). Effect of self-care guidelines on knowledge and quality of life among faculty of nursing students with vaginal infection. Obstetrics \& Gynecology International Journal, 10(1). https://doi.org/10.15406/ogij.2019.10.00408
\end{abstract}

Abdullah A., Sameera M. M., Dheya A., Hassan.A,and Raghad A et al,(2020). Prevalence and risk factor associated with vulvovaginal candidiasis, Universal Journal of Pharmaceutical Research, 5(3) p 1-5.

Ainee N, (2020). Suspect vaginal yeast infection? 5 home remedies help dealing with vaginal yeast infection, avilable at: https://www.healthshots.com/intimatehealth/feminine-hygiene/suspect-vaginalyeast-infection-five-home-remedies-helpdealing. Accessed on 1 Nov 2020, 5p.m

Center for disease control and prevention, (2018). vulvovaginal candidiasis available at: https://www.cdc.gov/std/tg2018/candidiasis.h $\underline{\mathrm{tm}}$, accessed on 22Dec,2020 6p.m.

De Sanctis, V., Rigon, F., Bernasconi, S., Bianchin, L., Bona, G., Bozzola, M., Buzi, F., De Sanctis, C., Tonini, G., Radetti, G., \& Perissinotto, E., (2019): Age at Menarche and Menstrual Abnormalities in Adolescence: Does it Matter? The Evidence from a Large Survey among Italian Secondary Schoolgirls. Indian Journal of Pediatrics, 86(February), 34-41. https://doi.org/10.1007/s12098-018-2822

Dharin S. A., Afif N., H., Samsriyaningsih H. and Evy E., (2018). Risk factors of vulvovaginal candidiasis in dermatovenereology outpatients clinic of Soetomo 
General Hospital, Surabaya, Indonesia, Afirican journal of infectiouse disease,12(1).

Eraky, E. M. (2018). The Effect of Supportive Nursing Instructions on Recurrence of Vulvovaginal Candidiasis Infection during Pregnancy. 6(6), 437-445.

Felix C., (2019). Alternative and complementary therapies for vulvovaginal candidiasis, Springer Link, Folia Microbiologica, 64(2) 133-141

Foxman, B. and Muraglia, R., (2016)."Prevalence of recurrent vulvovaginal candidiasis in 5 european countries and the united states: Results from an internet panel survey." Journal of Lower Genital Tract

Disease, vol. 17 , pp. 340-345.

Gonçalves B, Carina F., Carlos T., A., Mariana H., Joana A.,and Sónia S., (2016). Vulvovaginal candidiasis: Epidemiology, microbiology and risk factors National library of medicine,42(6) 905-27.

Gunther LSA, Martins HPR, Gimenes F, Abreu ALP, Consolaro MEL, Svidzinski TIE et al, (2018). Prevalence of Candida albicans and non-albicans isolates from vaginal secretions: comparative evaluation of colonization, vaginal candidiasis and recurrent vaginal candidiasis in diabetic and non-diabetic women. São Paulo Med J 132(2):116-120.

Kalia N, Singh J and Kaur M., (2020). Microbiota in vaginal health and pathogenesis of recurrent vulvovaginal infections: a critical review. Ann Clin Microbiol Antimicrob.;19(1):5.

Malfasari, E., Febtrina, R., Herniyanti, R., \& Utari, E. M., (2019). Effect of instructional program on knowledge regarding Vulvovaginal Candidiasis among female university students. Indonesian Journal of Global Health Research,
1(1), 59-72.

Michelle W., (2019). vaginal and vulval candidiasis available at: https://patient.info /doctor/ vaginal-and-vulval-candidiasis\#nav1, accessed on 1 Jan,2021 5p.m.

Moshfeghy, Z., Tahari, S., Janghorban, R., Najib, F. S., Mani, A., \& Sayadi, M., (2020). Association of sexual function and psychological symptoms including depression, anxiety and stress in women with recurrent vulvovaginal candidiasis. Journal of the Turkish German Gynecology Association, 21(2), 90-96.

Orabi, A., (2018). Assessing Knowledge Regarding Vulvovaginal Candidiasis among Female University Students. ATINER's Conference Paper Series, NUR2017-2433 An, $1-17$.

Reichman O, Margesson LJ, Rasmussen CA, Lev-Sagie A, Sobel JD. et al,(2019). Algorithms for managing vulvovaginal symptoms-a practical primer. Curr Infect Dis Rep. ;21(10): 40.

Said, S. A. E., Elbana, H. M., \& Salama, A. M., (2019). Education Intervention Guideline on Knowledge and Self-Care Practice for Women With Vulvovaginities. International Journal of Studies in Nursing, 4(1), 73.

Sharma, S., Deuja, S., \& Saha, C. G., (2016). Menstrual pattern among adolescent girls of Pokhara Valley: A cross sectional study. BMC Women's Health, 16(1), 1-6.

Şimşir, C., Coşkun, B., Coşkun, B., Erşahin, A. A., \& Ecemiş, T., (2019). Effects of bacterial vaginosis and its treatment on sexual functions: A cross-sectional questionnaire study. Archives of Clinical and Experimental Medicine, 4(2), 99-102. 
Singh, N., \& Singh, J., (2018). Study of Risk Factors for Infectious Vaginitis in Reproductive Women Section: Obstetrics and Gynecology. 5(12), 10-12.

Sobel JD.(2018). Recurrent vulvovaginal candidiasis. Am J Obstet Gynecol.;214(1):1521.

Sopian L. Shahabudin .S, Ahmed M.A and Sanda. D,(2018). yeast infection and diabetes millutes among women. 23(1): 27-34. PMCID: PMC4975586 PMID: 27540323

Youness A., E., \& Omar, A., (2017). Effectiveness of planned educational program on vaginitis and its preventive measures on adolescent female nursing student's knowledge. Egyptian Nursing Journal, 14(1), 1. 


\section{فاعلية صودا الخبز على عدوى الخميرة المهبلية لاى طلاب التمريض المراهقين}

$$
\text { إسر اء إبر اهيم عبدربهـ سعاد عبد السلام رمضان- ايمان محمد عبد الحكم-علا عبد الوهاب عفيفي }
$$

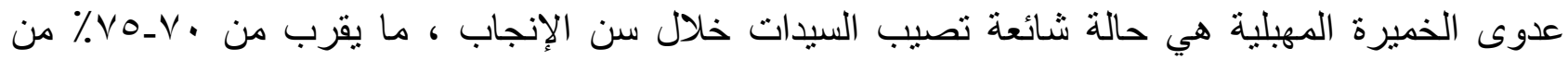

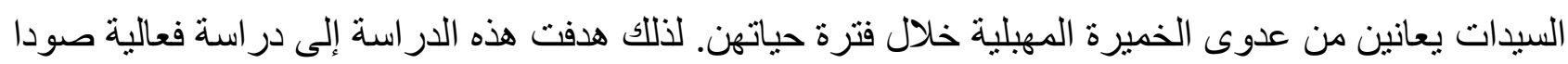

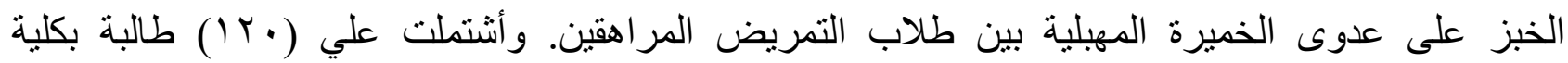
التمريض. حيث كثفت النتائج عن أن هناك فروق ذات دلالة إحصائية عالية بين نتائج مرحلة ما بعد التنخل

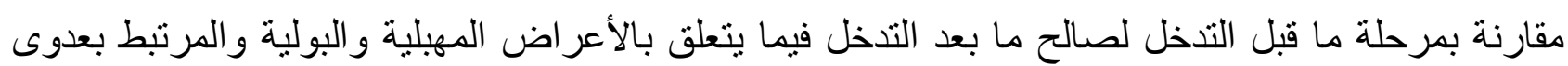

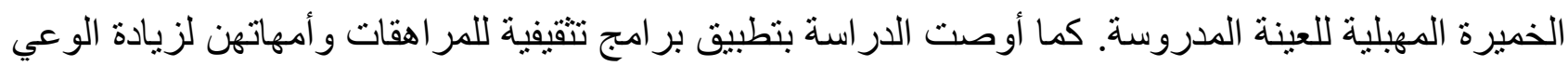

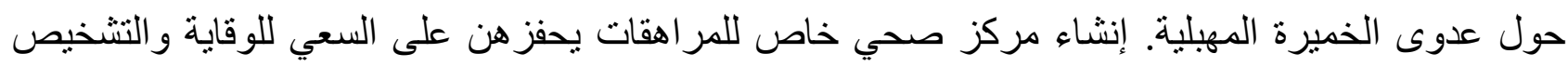
المبكر و علاج العدوى المهبلية التي قد يكون لها تأثثير إيجابي على صحتهن المستقبلية. 